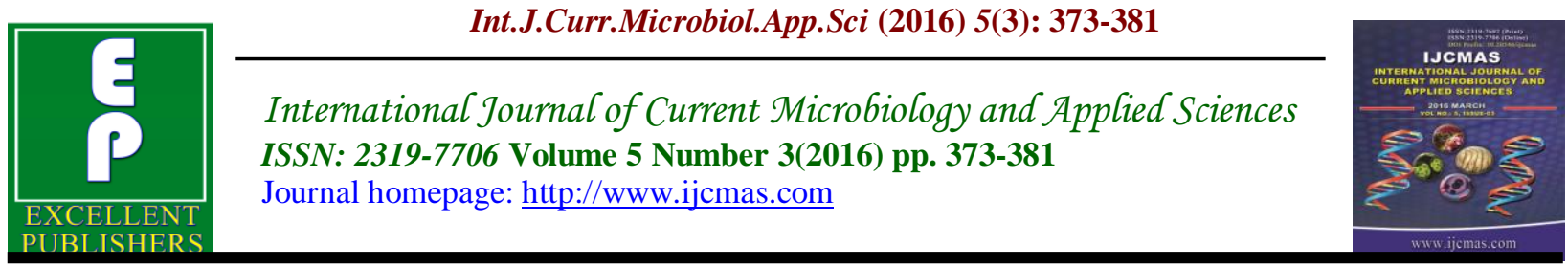

Original Research Article

http://dx.doi.org/10.20546/ijcmas.2016.503.044

\title{
Basic Core Promotor Mutations of HBV as Early Biomarkers for Hepatocellular Carcinoma in Egyptian Patients
}

\author{
Nermeen Tayseer Aly Fouad ${ }^{*}$, Dina ElShennawy ${ }^{1}$, Rania A. Abo-Shady ${ }^{1}$, Hossam M. Fahmy ${ }^{1}$, \\ Hala Ghareeb ${ }^{1}$, Rania H ElKabarity ${ }^{1}$, Marcel W. Keddeas ${ }^{2}$ and Amal T. Abdel Moez ${ }^{3}$ \\ ${ }^{1}$ Clinical Pathology department, Faculty of Medicine, Ain Shams University, Cairo, Egypt \\ ${ }^{2}$ Internal Medicine department, Faculty of Medicine, Ain Shams University, Cairo, Egypt \\ ${ }^{3}$ Tropical Medicine department, Faculty of Medicine, Ain Shams University, Cairo, Egypt \\ *Corresponding author
}

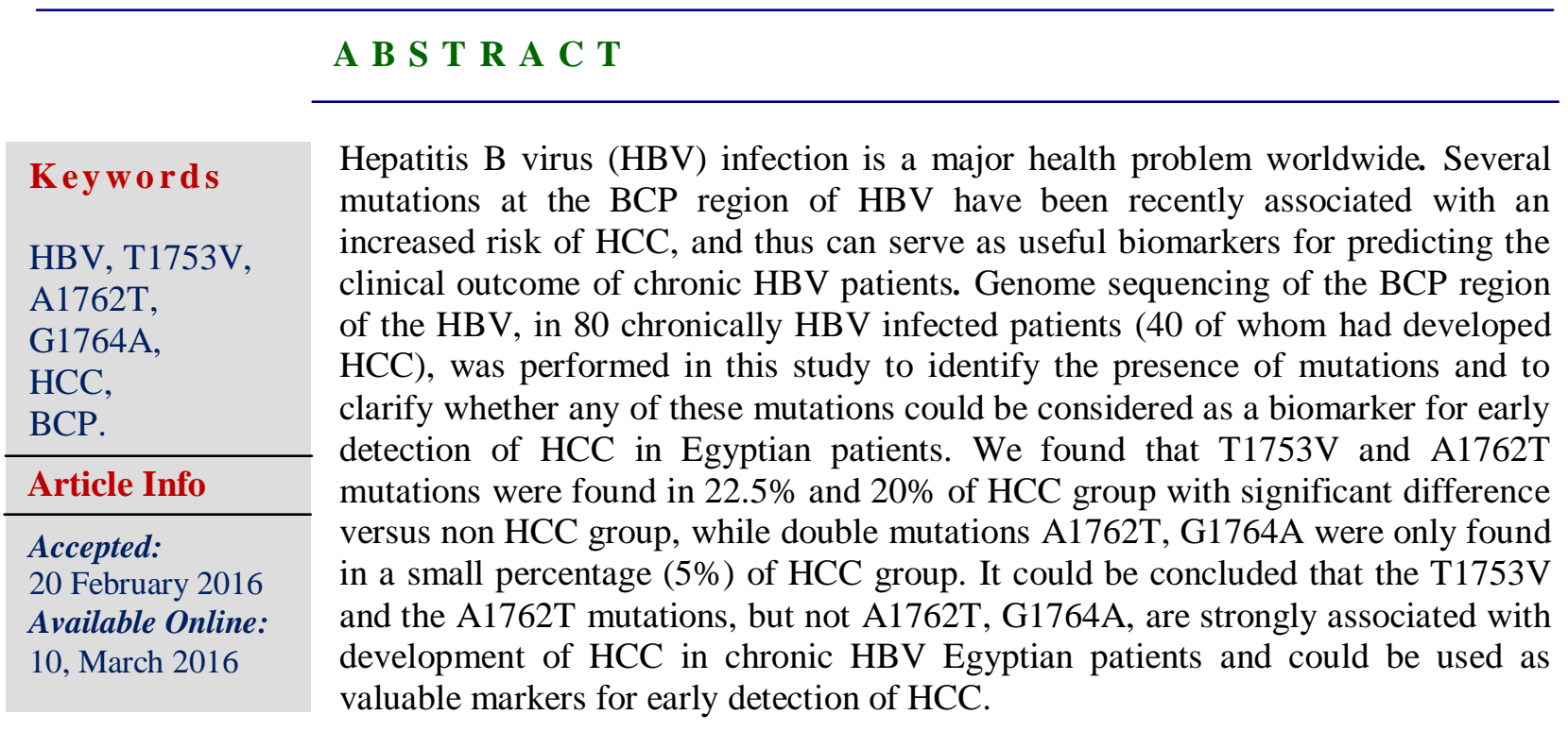

\section{Introduction}

Hepatitis B virus (HBV) infection is a global major health problem, with about 2-3 billion $\mathrm{HBV}$ infected cases worldwide. Some HBV cases can achieve complete clearance of virus, yielding a life-long immunity, while others can develop chronic HBV infection depending on the host immune response (Cooke, et al., 2010; Khan, et al., 2013). There are about 350 - 400 million chronically infected HBV cases worldwide, who have increased risk of developing end-stage liver disease as cirrhosis and hepatocellular carcinoma (HCC). HCC is considered the second main cause of cancerrelated deaths worldwide and its incidence is increasing in both developed and developing countries, including Egypt. In fact, HBV is considered one of the most important risk factors of HCC, as 70- $80 \%$ of HCC cases are associated with HBV infections (Khan, et al., 2013; Yang, et al., 2015). 
HBV belongs to the hepadnaviridae family, a family of enveloped viruses with an incomplete double stranded DNA genome. The HBV is more prone to mutations than the other DNA viruses due to its asymmetric replication via reverse transcription of an RNA intermediate and due to the lack of the proofreading function of its reverse transcriptase (Buti, et al, 2005). HBV genome is approximately $3.2 \mathrm{kbp}$ and it contains four main overlapping open reading frames (ORFs) that encode various $\mathrm{HBV}$ components; surface $(\mathrm{S})$, precore/core $(\mathrm{C})$, polymerase $(\mathrm{P})$, and $\mathrm{X}$ ORFs which encode the HBsAg, HBcAg and $\mathrm{HBeAg}$, polymerase protein, and the $\mathrm{X}$ regulatory protein respectively [5]. The $\mathrm{X}$ region is overlapped by both enhancer II (Enh II) (nucleotides 1685-1773) and the basic core promoter (BCP) (nucleotides 1751-1769) regions, known to have such important roles in viral replication (Yang, et al., 2015; Hakami, et al., 2013).

It is known that alteration of critical epitopes in HBV mutants could affect the viral recognition by the host immune system, its attachment to the host cells, its penetration ability, its replication, and the resistance to antiviral therapies (Yang, et al., 2015). In that context, several studies reported that mutations at the enh II, BCP and precore stop-codon regions, as A1762T/G1764A, C1653T, and T1753V mutations, were associated with worsen outcomes of $\mathrm{HBV}$ infection and increased risk of HCC among these patients, and that these mutations occur several years before the diagnosis of $\mathrm{HCC}$, a finding that suggests that these HBV mutations may serve as useful biomarkers for predicting the clinical outcome and HCC risk of HBV-infected patients (Yang, et al., 2015; Kim, et al., 2009; Lyu, et al., 2013; Wen, et al., 2015). However, contradictory observations were also reported (Khan, et al., 2013; Truong, et al., 2007).
The aim of the current study is to investigate the presence of mutations in the $\mathrm{BCP}$ region and their relationship with $\mathrm{HCC}$ aiming to clarify whether any of these mutations could be considered as a biomarker for early detection of HCC in Egyptian patients.

\section{Subjects and Methods}

Plasma and serum samples were collected from 80 chronic $\mathrm{HBV}$ patients, with $\mathrm{HBs} \mathrm{Ag}$ positive for more than 6 months, who attended Ain Shams University Hospitals. The patients were divided into two groups; group I (HCC group) that included 40 patients who had developed HCC on top of their chronic HBV infection, as proven by abdominal ultrasound (US), triphasic spiral C.T. scan, and alpha-fetoprotein testing, and group II, non HCC group, which included 40 cases with chronic HBV infection and no clinical, radiologic or serologic evidence of HCC.

Informed consent was obtained from all participant individuals. The study was conducted in accordance with the stipulations of the local ethical and scientific committees of Ain Shams University and the procedures respected the ethical standards in Helsinki declaration of 1964.

All patients were subjected to:

1. HBeAg detection (by Cobas e411, Roche Diagnostics, Indianapolis, USA )

2. $\mathrm{HBV} B C P$ region sequencing by $\mathrm{ABI}$ PRISM BigDye Terminator v3.1 Cycle Sequencing Kits, followed by sequence analysis using the automated sequencer; ABI PRISM 310 Genetic Analyzer (Applied Biosystems; USA). 
- HBV DNA extraction was done using (QIA amp Mini-Elute Virus Spin Kit, Qiagen, Valencia, California; USA), according to the manufacturer's instructions.

- $\quad$ HBV DNA amplification by nested PCR (for amplification of the BCP region) was performed using T-Professional Thermocycler (Biometra diagnostics, Goettingen; Germany). First stage PCR was performed using the outer sense primer (5'CTAGCCGCTTGTTTTGCTCG-3') and the outer antisense primer (5'CACAGCTTGGAGGCTTGAAC-3') for 35 cycles, with each cycle encompassing denaturation at $95^{\circ} \mathrm{C}$ for 60 seconds, annealing at $55^{\circ} \mathrm{C}$ for 30 seconds, and extension at $72^{\circ} \mathrm{C}$ for 60 seconds with final extension step at $72^{\circ} \mathrm{C}$ for $10 \mathrm{~min}$. A second stage PCR was then performed, where $1 \mu \mathrm{l}$ of the first PCR product was re-amplified using the inner sense primer (5'CTCATCTGCCGGACCGTGTG-3') and the inner antisense primer (5'TAGGACATGAACAAGAGATG-3'), for another 35 cycles, with same conditions as first stage PCR.

Then sequencing of the amplified product was done using the ABI PRISM BigDye Terminator v3.1 Cycle Sequencing Kit ready reaction (Applied Biosystems, USA) and the second stage primers by dideoxy method whereby the reaction tubes were put in the thermal cycler for 25 cycles, each consisted of Pre-naturation at $96^{\circ} \mathrm{C}$ for 60 seconds, entailed denaturation at $96{ }^{\circ} \mathrm{C}$ for 10 seconds, annealing at $50^{\circ} \mathrm{C}$ for 5 seconds, followed by extension at $60{ }^{\circ} \mathrm{C}$ for 4 minutes. An "ice-shock" was then done for the above samples for 2 minutes at $-80^{\circ} \mathrm{C}$ to allow stopping of the reaction.

Sequencing Analysis was done using the automated sequencer; ABI PRISM 310 Genetic Analyzer (Applied Biosystems;
USA) and "310 data collection software version 3.1.0." software.

\section{Statistical Analysis}

Statistical analysis was performed using SPSS V 15.0. Results were expressed as mean $\pm \mathrm{SD}$, percentages, and ranges. Fisher's exact test, Chi-square test, and odds ratio were used to compare the differences between qualitative variables among the 2 patients' groups (group I and II). A p-value of $\leq 0.05$ was considered to be statistically significant.

\section{Results}

The demographic and laboratory findings of the patients enrolled in the present study are presented in Table (1). The majority of participants (64/80) in both groups were males accounting for $77.5 \%$ and $82.5 \%$ of group I and group II patients respectively. The age of patients enrolled in this study ranged from 30- 79 years with a mean of $57.53 \pm$ 9.6. Group I patients were significantly older than group II patients (table 1). Mutations in the BCP were detected in total of $43 / 80$ chronic HBV patients enrolled in this study $(53.75 \%)$, $26 / 40$ (65\%) of group I patients (HCC group), and in $17 / 40(42.5 \%)$ of group II patients (non-HCC group). Comparative statistics between the 2 groups revealed significant difference as regards frequency of mutations (Table 1).

\section{HBeAg Status}

$60 / 80$ (75\%) patients enrolled in this study were $\mathrm{HBe} A g$ negative, (28 in group I (70\%), and 32 in group II $(80 \%)$ ), while $20 / 80$ (25\%) patients enrolled in this study were HBe Ag positive, (12 in group I and 8 in group 2), with no significant difference between both groups $(\mathrm{p}=0.439) .31 / 43$ (72.1\%) patients in both groups who have 
$\mathrm{BCP}$ mutation were $\mathrm{HBeAg}$ negative, while $29 / 37$ of patients $(78.3 \%)$ who don't have $\mathrm{BCP}$ mutation in both groups were $\mathrm{HBeAg}$ negative with no significant difference between them $(p=0.609)$.

\section{BCP Mutations}

The most common encountered mutation in the group I was substitution of $\mathrm{T}$ with $\mathrm{C} / \mathrm{G}$ at nucleotide position 1753, accounting for $(22.5 \%)$ of group I patients, while the most common encountered mutation in group II was substitution of $G$ with $A$ at nucleotide position 1764 accounting for $10 \%$ of group II patients.

Ten different types of mutations were encountered in the $80 \mathrm{HBV}$ enrolled in this study, whereas, 6 different types of mutations were detected in Group I, and 8 different types of mutations were encountered in group II.

\section{Mutations detected in group I only}

The following mutations were detected in group I but not in group II patients:
1. Substitution of $\mathrm{T}$ with $\mathrm{G}$ at nucleotide position 1768 (T1768G) in 4 cases (10\%).

2. Double mutations 1762/1764 (A1762T, G1764A) in 2 cases (5\%).

\section{Mutations Detected in Group II only}

The following mutations were detected in group II patients but not in group I patients:

1. Substitution of $\mathrm{T}$ with $\mathrm{A}$ at nucleotide position 1759 encountered in 3 cases $(7.5 \%)$.

2. Substitution of $\mathrm{T}$ with $\mathrm{G}$ at nucleotide position 1763 encountered in 3 cases $(7.5 \%)$.

3. Substitution of $\mathrm{A}$ with $\mathrm{T}$ at nucleotide position 1765 (A1765T) encountered in 2 cases $(5.0 \%)$.

4. Substitution of $\mathrm{G}$ with $\mathrm{A}$ at nucleotide position 1764 (G1764A) encountered in 4 cases $(10 \%)$.

Table.1 Demographic Features and Laboratory Findings of Group I and Group II Patients

\begin{tabular}{|lllll|}
\hline Parameter & Group I & Group II & p & Significance \\
\hline Age & & & & \\
Mean \pm SD & $61.43 \pm 7.44$ & $53.63 \pm 10.0$ & 0.01 & $\mathrm{~S}$ \\
Range & $(44-79)$ & $(30-78)$ & & \\
Frequency: & 0 & 3 & & \\
$30-40$ & 2 & 14 & & \\
$40-50$ & 16 & 12 & & \\
$50-60$ & 22 & 11 & 1.00 & $\mathrm{NS}$ \\
More than 60 & $9(22.5 \%)$ & $7(17.5 \%)$ & \\
Sex: & $31(77.5 \%)$ & $33(82.5 \%)$ & & \\
F & $28(70 \%)$ & $32(80 \%)$ & & \\
M & $12(30 \%)$ & $8(20 \%)$ & & \\
HBeAg positivity status: & $17(42.5 \%)$ & & \\
HBeAg negative & $26(65 \%)$ & & & \\
HBeAg positive & & & & \\
Mutations in BCP region &
\end{tabular}


Table.2 Comparative Statistics of Different Mutations in Group I Versus Group II

\begin{tabular}{|l|l|l|l|lc|}
\hline Type of Mutation & $\begin{array}{l}\text { Frequency of } \\
\text { mutation in group I } \\
(\mathbf{n}=\mathbf{4 0})\end{array}$ & $\begin{array}{l}\text { Frequency of } \\
\text { mutation in group II } \\
(\mathbf{n}=\mathbf{4 0})\end{array}$ & Odds ratio & $\mathbf{p}$ & significance \\
\hline All mutations & 26 cases $(65 \%)$ & 17 cases $(42.5 \%)$ & 2.51 & 0.0482 & $\mathrm{~S}$ \\
\hline A1762T & 8 cases $(20 \%)$ & 1 case $(2.5 \%)$ & 9.75 & 0.0289 & $\mathrm{~S}$ \\
\hline T1753V & 9 cases $(22.5 \%)$ & 2 cases $(5 \%)$ & 5.52 & 0.0476 & $\mathrm{~S}$ \\
\hline T1768G & 4 cases $(10.0 \%)$ & 0 case $(0 \%)$ & 9.99 & 0.0547 & $\mathrm{NS}$ \\
\hline A1761T & 3 cases $(7.5 \%)$ & 2 case $(5 \%)$ & 1.55 & 0.644 & $\mathrm{NS}$ \\
\hline $\begin{array}{l}\text { Double mutations } \\
\text { A1762T,G1764A }\end{array}$ & 2 cases $(5 \%)$ & 0 case (0\%) & 5.26 & 0.4934 & $\mathrm{NS}$ \\
\hline
\end{tabular}

*NS: non significant, S: significant

\section{Mutations Detected in Both Group I and II}

The following mutations were detected in both groups (Table 2):

1. Substitution of $\mathrm{A}$ with $\mathrm{T}$ at nucleotide position 1762 (A1762T).

2. Substitution of $\mathrm{T}$ with $\mathrm{C} / \mathrm{G}$ at nucleotide position $1753(\mathrm{~T} 1753 \mathrm{~V})$.

3. Substitution of $\mathrm{A}$ with $\mathrm{T}$ at nucleotide position 1761 (A1761T).

The frequency, odds ratios of different $\mathrm{BCP}$ mutations and their significance in group I versus group II are presented in Table (2).

\section{Discussion}

About $5 \%$ of the world population nowadays suffer from HBV infection that eventually leads to the death of almost million cases annually due to liver cirrhosis or HCC (Xie, et al., 2015; Hakami, et al., ). HCC, $80 \%$ of which triggered by $\mathrm{HBV}$ infection, has a very poor prognosis as its 5 years free survival rate is less than $20 \%$ (Yang, et al., 2015).

It is documented that $\mathrm{HBV}$ is more prone to mutation during its replication than other
DNA viruses, as its reverse transcriptase lacks proofreading function, and that these mutations accumulate over time and might have a pathogenic role (Buti, et al., 2005; Datta, et al., 2014). This was confirmed in our study by the high percentage of mutations encountered in HBV patients $43 / 80$ enrolled in our study $(53.75 \%)$.

It was reported that mutations particularly those of the $\mathrm{BCP}$ region, as $\mathrm{T} 1753 \mathrm{~V}$ and double mutation A1762T/G1764A, correlate with HBV related diseases' clinical outcomes and are invariably associated with HCC, as many critical sequences of the HBV genome, as Enh II and the X-terminal signal, are located in this region (Yuen, et al., 2009; Yin, et al., 2011). On the other hand, other published studies showed a negative association between these mutations and HCC (Khan, et al., 2013). Genome sequencing of the $\mathrm{BCP}$ region of the HBV, in 80 chronically HBV infected patients (40 of whom developed HCC), was performed in this study to determine the exact sequence of this region and identify the presence of any mutations and to clarify whether any of these mutations could be considered as a biomarker for early detection of HCC in Egyptian patients. We were able to detect the T1753V mutation in $22.5 \%$ of HCC group I patients and in only $5 \%$ in the non HCC group II patients, with 
an odds ratio of 5.516 and significant difference between the 2 groups, which indicates that $\mathrm{T} 1753 \mathrm{~V}$ mutation is associated with 5.52 fold increased risk to develop HCC. This was in accordance with results of other previous studies (Yang, et al., 2015; Shinkai, et al., 2007; Liao, et al., 2012), who concluded that the presence of $\mathrm{T} 1753 \mathrm{~V}$ mutation was associated with increased risk to develop HCC (odds ratio was 2.09, 7.95, and 2.19 respectively). On the other hand, Khan and his associates (Khan, et al., 2013) reported the presence of $\mathrm{T} 1753 \mathrm{C}$ mutation in $35.5 \%$ and $40 \%$ of $\mathrm{HCC}$ and non $\mathrm{HCC}$ patients respectively, with a higher incidence of non-HCC. Regarding mutation at position 1762, and in agreement with other studies (Chen, et al., 2013), it was found that $20 \%$ of HCC patients (group I) in this study had A1762T mutation versus $2.5 \%$ of the non HCC patients (group II), with a significant difference between the 2 groups and an odds ratio of 9.75. These findings suggest that both $\mathrm{T} 1753 \mathrm{~V}$ and A1762T could possibly be predictive markers for early detection of HCC.

On the other hand, contrary to the results of other previous studies (Yang, et al., 2015; Liao, et al., 2012; Lin, et al., 2005; Liu, et al., 2009), which reported that the BCP "A1762T/G1764A" double mutations were associated with a higher risk to develop HCC, the "A1762T/G1764A" double mutations were found in only 2 patients (5\%) of group I and in $0 \%$ of group II patients in the current study, with nonsignificant difference between both groups.

Similarly, Constantinescu and his colleagues (Constantinescu, et al., 2014), reported a non-significant difference of "A1762T/ G1764A" double mutations in HCC versus non HCC chronic HBV patients. Moreover, they reported a higher incidence of this mutation in the non-HCC group than in HCC group (12.5\% and $9.5 \%$ respectively).
This controversy might be partially due to the relatively small number of cases included in this study. In addition, this mutation could be associated with specific viral genotypes or sub-genotypes that may not be common in Egypt. This speculation is supported by the fact that most of the studies (Yang, et al., 2015; Liao, et al., 2012; Lin, et $a l ., 2005)$, that reported the association of this mutation with HCC were done in Southeast Asia where $\mathrm{B}$ and $\mathrm{C}$ are the dominant genotypes of HBV (Wen, et al., 2015; Park, et al., 2014; Sunbul, 2014), whereas in Egypt, Mediterranean, and Middle East regions, A \& D are the most prevalent genotypes of HBV (Khan, et al., 2013;Constantinescu, et al., 2014; Sunbul, 2014).

Furthermore, the study done in Romania revealed non-significant association of this mutation with HCC particularly in association with $\mathrm{A}$ and D HBV genotypes (Constantinescu, et al., 2014;).

We also found that the $\mathrm{T} 1768 \mathrm{G}$ mutation occurred in $10 \%$ of cases in HCC group and had not been detected in the non-HCC group, with a non-significant difference between both groups and an odds ratio of 9.99. Similarly, Li, et al. (2013) found a different point mutation "G1768A" at the same 1768 position and concluded that the T1768A mutation is associated with increased risk for HCC. Moreover, Khan and his associates described that other novel mutations, as G1727, C1741, C1773T, and the triple mutation "A1757T/C1764/ G1766", were significantly associated with HCC (Khan, et al., 2013). The diversity of the HBV genome mutation are attributed to the high mutation nature of the HBV and geographical difference in HBV genotypes. However, extended studies are needed to clarify the significance of $\mathrm{T} 1768 \mathrm{G}$ mutation in association with HCC in Egypt. 
The exact underlying mechanisms of these mutations and their impact on the pathogenesis of hepatocarcinogenesis are not clearly defined (Yang, et al., 2015). Nucleotides 1753, 1762, and 1764 in HBV genome are possibly the binding sites of many familiar liver specific nuclear regulating factors, enhancer-binding proteins and transcription factors, so mutations at these sites would possibly alter the binding capability of these regulating factors, and thus may be involved in the pathogenesis of HCC. Moreover, mutations in the BCP region of $\mathrm{HBV}$ genome could lead to increase HBV replication. Furthermore, these mutations may activate oncogenes and initiate hepatocarcinogenesis by altering the amino acids sequence of the regulatory $\mathrm{X}$ protein (Yang, et al., 2015; Hakami, et al., 2013; Yang, et al., 2008).

In contrast to other studies (Park, et al., 2014), no significant correlation was found in this study between $\mathrm{HBeAg}$ positivity or the occurrence of mutations in either group nor with the occurrence of HCC.

It could be concluded that the $\mathrm{T} 1753 \mathrm{~V}$ and the A1762T mutations are strongly associated with the development of HCC in Egyptian chronic HBV patients and could be valuable markers for early detection of HCC, while double mutations A1762T/G1764A appear to have no significant association with $\mathrm{HCC}$ in Egyptian patients, but need further validation by extended studies involving large numbers of Egyptian patients. Meanwhile, mutation T1768G needs further validation through detection of the exact viral genotype and sub-genotype.

\section{References}

Cooke, G.S., Main, J., Thursz, M.R. Treatment for hepatitis B. BMJ., 340: 5429.
Khan, A., Al Balwi, M., Tanaka, Y., Hajeer, A., Sanai, F., Al Abdulkarim, I., Latifah Al Ayyar, L., Badri, M., Saudi, D., Tamimi, W., Mizokami, M., Al Knawy, B. 2013. Novel point mutations and mutational complexes in the enhancer II, core promoter and precore regions of hepatitis $\mathrm{B}$ virus genotype D1 associated with hepatocellular carcinoma in Saudi Arabia. Int. J. Cancer., 133: 28642871.

Yang, Y., Sun, J., Zhao, L.G., Bray, F., Xiang, Y.B. 2015. Quantitative evaluation of hepatitis B virus mutations and hepatocellular carcinoma risk: a meta-analysis of prospective studies. Chin. J. Cancer Res., 27(5): 497-508.

Buti, M., Rodriguez-Frias, F., Jardi, R., Esteban, R. 2005. Hepatitis B virus genome variability and disease progression: the impact of pre-core mutants and HBV genotypes. J. Clin. Virol., 34(1): S79-82.

Xie, Y., Liu, S., Zhao, Y., Zhang, L., Zhao, Y., Liu, B., Guo, Z. 2015. Precore/Core Region Mutations in Hepatitis B Virus DNA Predict Postoperative Survival in Hepatocellular Carcinoma. PLoS One., 10(7): e0133393.

Hakami, A., Ali, A., Hakami, A. 2013. Effects of Hepatitis B Virus Mutations on its Replication and Liver Disease Severity. Open Virol. J., 7: 12-18.

Kim, J.K., Chang, H.Y., Lee, J.M., Baatarkhuu, O., Yoon, Y.J., Park, J.Y., Kim do, Y., Han, K.H., Chon, C.Y., Ahn, S.H. 2009. Specific mutations in the enhancer II/core promoter/precore regions of hepatitis $B$ virus sub genotype $\mathrm{C} 2$ in Korean patients with hepatocellular carcinoma. J. Med. Virol., 81(6): 1002-1008. 
Lyu, H., Lee, D., Chung, Y.H., Kim, J.A., Lee, J.H., Jin, Y.J., Park, W., Mathews, P., Jaffee, W., Zheng, L., Yu, E., Lee, Y.J. 2013. Synergistic Effects of A1896, T1653 and T1762/A1764 Mutations in Genotype C2 Hepatitis B Virus on Development of Hepatocellular Carcinoma. J. Viral. Hepat., 20(3): 219-224.

Wen, J., Song, C., Jiang, D., Jin, T., Dai, J., Zhu, L., An, J., Liu, Y., Ma, S., Qin, N., Liang, C., Chen, J., Jiang, Y., Yang, L., Liu, J., Liu, L., Geng, T., Chen, C., Jiang, J., Chen, J., Zhu, F., Zhu, Y., Yu, L., Shen, H., Zhai, X., $\mathrm{Xu}$, J., Hu, Z. 2015. Hepatitis B virus genotype, mutations, human leukocyte antigen polymorphisms and their interactions in hepatocellular carcinoma: a multi-center case control study. Sci. Rep., 5: 16489.

Truong, B.X., Yano, Y., Seo, Y., Phuong, T.M., Tanaka, Y., Kato, H., Miki, A., Utsumi, T., Azuma, T., Trach, N.K., Mizokami, M., Hayashi, Y., Kasuga, M. 2007. Variations in the core promoter/pre-core region in $\mathrm{HBV}$ genotype $\mathrm{C}$ in Japanese and Northern Vietnamese patients. J. Med. Virol., 79(9): 1293-1304.

Datta, S., Ghosh, A., Dasgupta, D., Ghosh, A., Roychoudhury, S., Roy, G., Das, S., Das, K., Gupta, S., Basu, K., Basu, A., Datta, S., Chowdhury, A., Banerjee, S. 2014. Novel Point and Combo-Mutations in the Genome of Hepatitis B Virus-Genotype D: Characterization and Impact on Liver Disease Progression to Hepatocellular Carcinoma. PLoS One., 9(10): e110012.

Yuen, M.F., Tanaka, Y., Fong, D.Y., Fung, J., Wong, D.K., Yuen, J.C., But, D.Y., Chan, A.O., Wong, B.C., Mizokami, M., Lai, C.L. 2009. Independent risk factors and predictive score for the development of hepatocellular carcinoma in chronic hepatitis B. $J$. Hepatol., 50: 80-88.

Yin, J., Xie, J., Liu, S., Zhang, H., Han, L., Lu, W., Shen, Q., Xu, G., Dong, H., Shen, J., Zhang, J., Han, J., Wang, L., Liu, Y., Wang, F., Zhao, J., Zhang, Q., Ni, W., Wang, H., Cao, G. 2011. Association between the various mutations in viral core promoter region to different stages of hepatitis B, ranging of asymptomatic carrier state to hepatocellular carcinoma. Am. J. Gastroenterol., 106(1): 81-92.

Shinkai, N., Tanaka, Y., Ito, K., Mukaide, M., Hasegawa, I., Asahina, Y., Izumi, N., Yatsuhashi, H., Orito, E., Joh, T., Mizokami, M. 2007. Influence of hepatitis B vir us X and core promoter mutations on hepatocellular carcinoma among patients infected with sub genotype C2. J. Clin. Microbiol., 45(10): 3191-3197.

Liao, Y., Hu, X., Chen, J., Cai, B., Tang, J., Ying, B., Wang, H., Wang, L. 2012. Precore Mutation of Hepatitis B Virus May Contribute to Hepatocellular Carcinoma Risk: Evidence from an Updated Meta-Analysis. PLoS one., 7(6): e38394.

Chen, Y.M., Wu, S.H., Qiu, C.N., Yu, D.J., Wang, X.J. 2013. Hepatitis B virus subgenotype C2- and B2-associated mutation patterns may be responsible for liver cirrhosis and hepatocellular carcinoma, respectively. Braz. J. Med. Biol. Res., 46(7): 614-622.

Lin, C.L., Liao, L.Y., Wang, C.S., Chen, P.J., Lai, M.Y., Chen, D.S., Kao, J.H. 2005. Basal core promoter mutant of hepatitis B virus and progression of liver disease in hepatitis B e antigennegative chronic hepatitis B. Liver Int., 25: 564-570.

Liu, S., Zhang, H., Gu, C., Yin, J., He, Y., Xie, J., Cao, G. 2009. Associations 
between hepatitis B virus mutations and the risk of hepatocellular carcinoma: a meta-analysis. J. Nat. Cancer Inst., 101(15): 1066-1082.

Constantinescu, I., Dinu, A.A., Boscaiu, V., Niculescu, M. 2014. Hepatitis B and Hepatocellular Carcinoma in Bucharest, Romania. Hepat. Mon., 14(10): e22072.

Park, Y.M., Jang, J.W., Yoo, S.H., Kim, S.H., Oh, I.M., Park, S.J., Jang, Y.S., An Lee, S.J. 2014. Combinations of eight key mutations in the $\mathrm{X} /$ preC region and genomic activity of hepatitis B virus are associated with hepatocellular carcinoma. J. Viral. Hepat., 21: 171-177.

Sunbul, M. 2014. Hepatitis B virus genotypes: global distribution and clinical importance. World $J$. Gastroenterol., 20: 5427-5434.

Li, W., Chen, G., Yu, X., Shi, Y., Peng, M., Wei, J. 2013. Accumulation of the mutations in basal core promoter of hepatitis B virus sub genotype C1 increase the risk of hepatocellular carcinoma in Southern China. Int. J. Clin. Expl. Pathol., 6(6): 1076-1085.

Yang, H.I., Yeh, S.H., Chen, P.J., Iloeje, U.H., Jen, C.L., Su, J., Wang, L.Y., Lu, S.N., You, S.L., Chen, D.S., Liaw, Y.F., Chen, C.J. 2008. Associations between hepatitis B virus genotype and mutants and risk of hepatocellular carcinoma. J. Nat. Cancer Inst., 100: 1134-1143.

\section{How to cite this article:}

Nermeen Tayseer Aly Fouad, Dina ElShennawy, Rania A. Abo-Shady, Hossam M. Fahmy, Hala Ghareeb, Rania H. ElKabarity, Marcel W. Keddeas and Amal T. Abdel Moez. 2016. Basic Core Promotor Mutations of HBV as Early Biomarkers for Hepatocellular Carcinoma in Egyptian Patients. Int.J.Curr.Microbiol.App.Sci. 5(3): 373-381. doi: http://dx.doi.org/10.20546/ijcmas.2016.503.044 